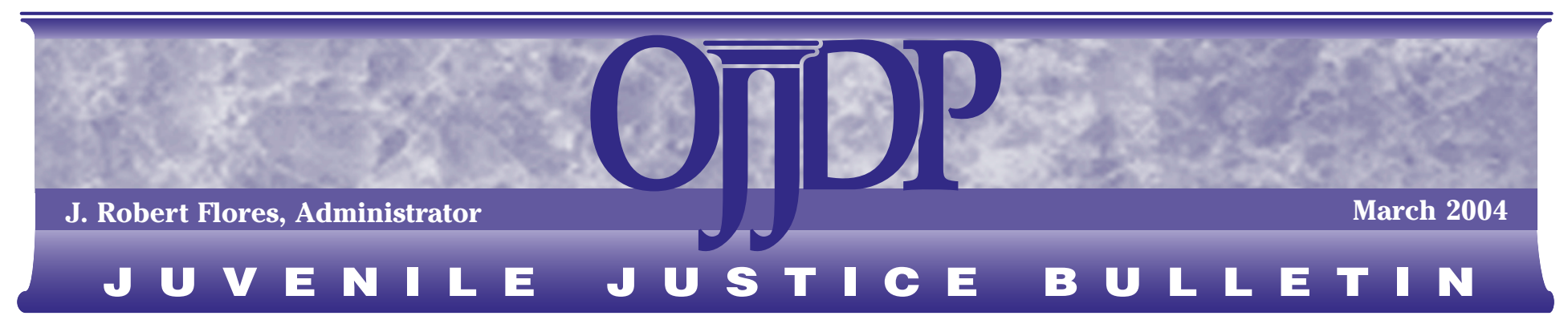

\title{
Youth Gangs in Indian Country
}

\section{Aline K. Major, Arlen Egley, Jr., James C. Howell, Barbara Mendenhall, and Troy Armstrong}

Recent studies have reported alarming levels of violence in Indian country. ${ }^{1}$ Researchers have found that American Indians and Alaska Natives experience a crime rate of 656 incidents per 100,000 residents, compared with a crime rate of 506 incidents per 100,000 residents in the general U.S. population (Hickman, 2003). In addition, Indian country communities suffer from a violent crime rate that is two to three times greater than the national average (Wakeling et al., 2001). The escalation of violence among youth in these areas is of particular concern to juvenile justice officials and community members (Greenfeld and Smith, 1999; Wakeling et al., 2001). Anecdotal reports and official records from juvenile justice officials (i.e., tribal courts and probation and law enforcement officers) in a number of Indian country communities indicate increased levels of crime associated with youth gangs. Each year since 1995, the National Youth Gang Center (NYGC) has surveyed law enforcement agencies throughout the country about gang activity. However, tribal police departments are not included in the survey sample, and detailed data

\footnotetext{
1 "Indian country" is defined in 18 U.S.C. $§ 1151$ as including (1) land within Indian reservations, (2) dependent Indian communities, and (3) Indian allotments.
}

about youth gang activity in Indian country have been largely absent.

In 2001, NYGC developed and implemented the 2000 Survey of Youth Gangs in Indian Country (see "Survey Design and Method" for a detailed discussion of the survey). All federally recognized Indian communities were surveyed to measure the presence, size, and criminal behavior of youth gangs in Indian country. This Bulletin presents data regarding the presence and effect of youth gang activity in Indian country and provides an overview of programmatic responses to the problem. When appropriate, the Bulletin compares findings from this survey to those from a national sample and a subset of jurisdictions that closely resemble Indian country communities in size and geographic location. The survey findings are also compared to relevant contextual data from a field study of gangs in the Navajo Nation (Armstrong et al., 2002).

\section{Survey Sample and Response}

At the time the survey was developed, there were 577 Indian communities in the United States, comprising 561 federally recognized tribes (figure 1, page 3 ). NYGC and the advisory group chose to survey

\section{A Message From OJJDP}

Since 1995, the National Youth Gang Center (NYGC) has surveyed law enforcement agencies across the nation about youth gang activity. Because tribal police departments were not included in earlier surveys, however, youth gang activities in Indian country have been largely absent from survey findings.

This Bulletin describes the nature and makeup of youth gangs in Indian country. The findings presented are the result of a 2001 NYGC surveytailored specifically for Indian communities-that asked federally recognized Indian communities to describe their experiences with youth gang activity. Researchers found that youth gangs in Indian country did not differ greatly from youth gangs in comparably sized communities. Indian country youth gangs, however, were noticeably different from youth gangs as depicted through national statistics. The study also included comparisons with findings from a previous study of youth gang activity in the Navajo Nation.

Drawing on these research findings, the Bulletin proposes prevention, intervention, and suppression strategies. These proposals are derived from effective programs in non-Indian country settings. Although such programs may require modification to better serve tribal communities, they provide Indian country leaders with proven methods to address emerging youth gang issues. 


\section{Survey Design and Method}

Before designing the 2000 Survey of Youth Gangs in Indian Country, the National Youth Gang Center (NYGC) consulted earlier research on gang activity in Indian country communities. This research was extremely limited and consisted mainly of a small number of descriptive reports that reference gangs (Nielson, Zion, and Hailer, 1998; Coalition for Juvenile Justice, 2000) and regional and national surveys (Hailer, 1998; Juneau, 1997, 1998).

Findings from two surveys conducted by the Bureau of Indian Affairs (BIA) in 1997 and 1998 included law enforcement contacts, a brief description of the local gang situation, and the types of criminal activity associated with gang members (Juneau, 1997, 1998). The later survey, which focused on Indian country communities in the West, Northwest, and Dakotas, covered basic definitions, names and locations of specific gangs, gang-related crime, and law enforcement responses to gang activity (Juneau, 1998).

One of the more comprehensive studies included findings from data gathered via a survey of tribal and BIA law enforcement agencies serving Indian country communities (Hailer, 1998). This study provided a baseline assessment of the extent of gang presence, gang characteristics, and law enforcement responses to gangs in Indian country communities. Additionally, a field study of youth gangs in the Navajo Nation provided data from interviews with gang members and agency stakeholders, results of community focus group meetings, an examination of relationships and influences from outside the reservation, and an explanation of the relationship between cluster housing and gang formation (Armstrong et al., 2002).

Although previous research helped shape the survey approach, NYGC determined that further consultation with other knowledgeable sources was necessary before the survey's actual development and implementation. NYGC decided to draw on the knowledge of experts in the field to ensure that related social issues were covered and that the survey language and data collection effort were sensitive to cultural differences. NYGC consulted with advisors from federal agencies and tribal organizations as it developed the study methodology and survey instrument. Advisory group participants included NYGC research staff, researchers from the Center for Delinquency and Crime Policy Studies, representatives from BIA and the Department of Justice, and staff from the Department of Housing and Urban Development, the Department of Health and Human Service's Indian Health Services, the National American Indian Court Judges Association, and the National Congress of American Indians. The advisory group recommended the most appropriate methods for collecting data, the unit of measurement, how to construct questions to ensure cultural sensitivity, and whom to target for communitywide information.

Data regarding gang activity are frequently collected from law enforcement officials. In this case, because NYGC wanted to ensure that respondents represented the communities surveyed, it decided a tribal leader would be the initial contact. To increase response rates, NYGC later solicited responses from law enforcement agencies serving those communities that had not responded to the initial inquiry.

\section{Survey Definitions}

To ensure that the survey measured what it was designed to measure, NYGC asked the advisory group to define critical concepts in the survey. This Bulletin refers to each respondent tribe, reservation, and Alaska Native village as a "community," which includes a wide range of settingspueblos, rancherias, villages, towns, and rural settlements. ${ }^{1}$ Specifically, the survey defines an Indian "community" as:

Persons of American Indian, Alaska Native, or Aleut heritage who

1 In 2001, the Bureau of Indian Affairs provided NYGC with a list of communities then recognized by the agency. This list represented the 561 recognized tribes in the form of 577 communities for which information pertaining to tribal enrollment was individually maintained. NYGC surveyed these communities. reside within the limits of Indian reservations, pueblos, rancherias, villages, dependent Indian communities, or Indian allotments, and who together comprise a federally recognized tribe or community. Communities also include people who have been recognized by the United States government as a tribe or tribal community, but who do not occupy tribal trust, tribally owned, or Indian allotment lands. Communities are the people and land together or tribal community viewed as a group. Land without the people is not considered a community for the purpose of this survey.

As used in this Bulletin, the concept of community in Indian country applies to a broad spectrum of land and people. Tribes and reservations vary greatly by size, configuration, and the settlement pattern that defines living arrangements. Indian communities located on a contiguous single piece of land containing just one occupied area or only a few occupied areas are similar to neighborhoods or small towns where the inhabitants and the area of land they occupy make up the community. This is the most common setting for Indian communities; however, different community configurations are located throughout Indian country.

Large reservations or more populous tribes located on either a contiguous single piece of land or noncontiguous pieces of land may include towns of various sizes and areas of more dispersed population. Outside of Indian country, these towns and rural areas might be considered separate communities. However, because of the residents' tribal connection, they are all considered members of one community in this Bulletin. A tribal community (people and land) also may be located in the midst of an urban setting. Some reservation trust lands ${ }^{2}$ are occupied by more than one tribe. These may

2 Reservation trust lands refer to areas that have been set aside and recognized by the federal government as being held in trust for a particular federally recognized tribe. A variety of federal treaties, regulations, and acts over the years have established these trust areas and have established laws governing sovereign Indian nations. 
have joint or confederated tribal administrative operations, whereas others maintain separate administrations for the different tribes living on the same reservation.

Despite commonly identified features of a youth gang, codified definitions vary (Curry and Decker, 2003; Spergel and Bobrowski, 1990). Using an approach similar to the National Youth Gang Survey (NYGS), this survey defines a "youth gang" as "a group of youths or young adults in your community that you or other responsible tribal members or service providers are willing to identify or classify as a 'gang." Therefore, this survey measures youth gang activity as an identified problem among interested community agents. To better understand how respondents defined youth gangs, a series of survey questions asked respondents about the characteristics that guide communities in identifying youth gangs (results are discussed on page
9). As in NYGS, respondents were asked to exclude motorcycle gangs, hate or ideology groups, prison gangs, or other exclusively adult gangs, which are beyond the scope of this survey.

\section{United States Census Data}

NYGC obtained 2000 population figures for Indian country communities from the United States Census Bureau. ${ }^{3}$ Population data used for this study included only persons who resided within the boundaries of a federally recognized Indian community. For communities in which this figure could not be accurately discerned, population figures were not used. Eighty-four percent ( $n=483$ ) of the total 577 communities were matched to the population data.

3 The data sets used were the Census 2000 Redistricting Data Summary File for All American Indian Areas and Alaska Native Areas and the Census 2000 Summary File 1 for American Indian and Alaska Native Areas.

\section{Survey of Youth Gangs in Indian Country}

The final survey instrument was developed using earlier research and input from advisory group meetings. The 2000 Survey of Youth Gangs in Indian Country included questions about the presence or absence of gangs and demographic data regarding gang members and their involvement in criminal activity. General questions about the community, pressing social problems, and law enforcement services were also included.

After the survey was finalized, but before its dissemination, a letter was sent to several associations and organizations soliciting support for the survey. A letter was also mailed to all tribal leaders explaining the purpose of the survey and requesting a contact to whom it could be sent. These initial efforts were beneficial to the survey process and helped establish awareness of survey objectives. the entire Indian country population to provide a broad assessment.

NYGC initially mailed the survey to tribal leaders and requested that they complete the survey or forward it to the tribal representative most capable of completing it. Contacting tribal authorities in some of the communities was a difficult task for a number of reasons. Infrequent or sporadic mail delivery made reaching potential respondents in isolated locations difficult. In some areas, tribal authorities were away from the community or otherwise unavailable because the survey was mailed during the height of the community's working season. In these cases, subordinates were often reluctant to speak on behalf of the community. These difficulties adversely affected the number of communities that responded to the survey and resulted in a reduced number of responses. NYGC staff made followup phone calls to tribal leaders and appropriate law enforcement officers in communities that had not responded.

Overall, 52 percent $(n=300)$ of the communities responded to the survey. In general, communities that responded to the survey represented more populated areas, thus providing data for more of the total

\section{Figure 1: Number of Federally Recognized Indian Communities in the United States, 2000, by State}

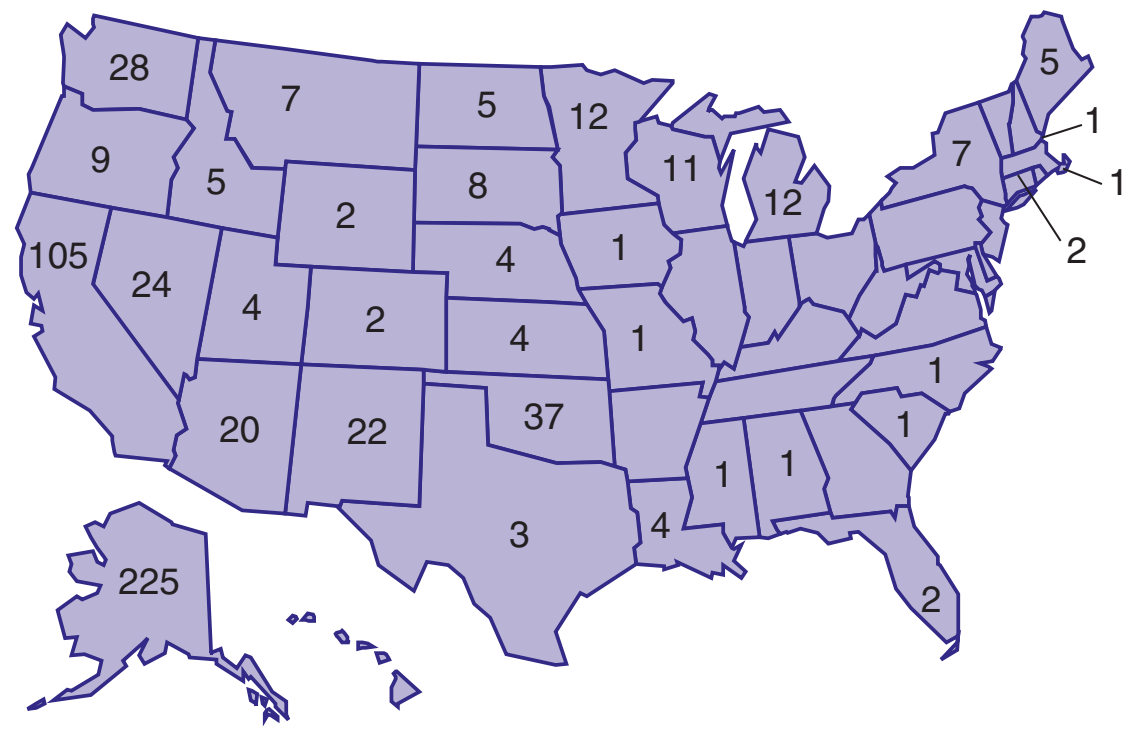

Source: Tribal enrollment list from the Bureau of Indian Affairs, submitted to NYGC in 2001. 
Indian country population than suggested by the 52 -percent response rate. It should be noted that survey findings in this Bulletin are based on completed surveys only and cannot necessarily be generalized to represent Indian communities on a national scale. However, this study provides the most inclusive picture to date of gangs in Indian country.

To provide a context for understanding gangs in Indian country, two additional samples are discussed throughout this Bulletin. First, NYGC's annual national survey of law enforcement agencies measures the gang problem throughout the United States. This national sample provides a means for comparing gang activity in Indian country and gang activity in the remainder of the nation. Second, to draw a more reasonable comparison between the national sample and the Indian country sample, NYGC selected a subsample of national respondents that shares a number of characteristics with Indian country communities. Thus, the Bulletin includes the following samples:

- Indian country sample: The 577 Indian communities comprising 561 federally recognized tribes.

- National sample: More than 3,000 law enforcement agencies consisting of police departments serving cities with populations of 25,000 or more, suburban county police and sheriff's departments, randomly selected police departments serving cities with populations between 2,500 and 24,999, and randomly selected rural county police and sheriff's departments.

- Comparison sample: A subsample of national respondents in nonmetropoli$\tan$ areas with populations of less than 25,000 .

\section{Findings}

\section{Law Enforcement Services}

Law enforcement arrangements in Indian country vary from community to community (Wakeling et al., 2001). To measure this variation, the survey asked respondents $(n=300)$ about the types of law enforcement services available in their community. Respondents could indicate the presence of more than one service. Survey responses revealed that tribal law enforcement services were the most common (43 percent of surveyed communities reported having this service), followed by Public Law 280 services $^{2}$ (35 percent); "other" services such as city/county law enforcement, state police, and the Federal Bureau of Investigation (32 percent); Bureau of Indian Affairs (BIA) law enforcement services (26 percent); and contracted law enforcement (9 percent).

Law enforcement services in Indian country have been characterized in previous research as having limited resources and other problems: for example, officer-toresident ratios that often do not exceed 2 officers per 1,000 residents; complicated jurisdictional policing authority that depends on the crime committed, the offender, the victim, and the location; and increasing crime rates without an equivalent increase in law enforcement personnel (Wakeling et al., 2001; Hickman, 2003). Given these difficulties, many departments find combating the social problems associated with violence and victimization (including youth gang activity) in these areas to be an arduous task.

Of special concern is the lack of sufficient crime data for these communities, which often prevents them from addressing crime problems effectively. Currently, the Tribal Justice Statistics Assistance Center, operated by the Justice Research and Statistics Association and funded by the Bureau of Justice Statistics, provides training and technical assistance for Indian country communities that wish to collect and use statistics more productively (Hickman, 2003). However, policing in Indian country remains an area that requires attention. A collaborative effort among tribal communities, researchers, and policymakers is needed to alleviate the problems faced by tribal communities and to provide effective policing in Indian country (Wakeling et al., 2001).

\section{Youth Gang Activity}

Twenty-three percent ( $n=69)$ of Indian country respondents ${ }^{3}$ reported having active youth gangs in their communities during 2000. Seventy percent responded that there was no gang activity in their communities, and 7 percent could not make a determination. ${ }^{4}$

2 Public Law 280 is a federal statute that grants a state in which an Indian community is located authority over criminal and civil matters on that land.

3 For the remainder of this Bulletin, "respondents" refers only to those communities reporting youth gang activity in 2000

4 Communities reporting "do not know" are presented here because of their appreciable number. Unless noted elsewhere in this Bulletin, "do not know" responses are excluded from the analysis.
NYGC obtained population data for 83 percent $(n=57)$ of the communities reporting gang activity. Although only 23 percent of responding Indian country communities reported active gangs, the residents located in these communities accounted for more than 60 percent of the total responding population. The average population of communities reporting gang activity was slightly more than 4,500 , compared with a population of slightly fewer than 400 among communities reporting no active gangs. This suggests that larger Indian country communities are more likely to experience gang activity than smaller communities.

By contrast, law enforcement agencies responding to the 2000 NYGC national survey noted a considerably greater degree of youth gang activity, with 40 percent $(n=975)$ of respondents indicating active youth gangs (Egley and Arjunan, 2002). Of the national survey respondents that were similar in size to the Indian country respondents (i.e., the comparison sample), 20 percent $(n=85)$ reported youth gang activity in their jurisdiction. ${ }^{5}$ Figure 2 compares gang activity across the three samples.

\section{Gangs and Gang Members}

Figures 3 and 4 (pages 5 and 6) show the number of gangs and gang members, respectively, in Indian country communities. The estimated number of youth gangs per community ranged from 1 to 40 , with the majority of respondents (59 percent of gang problem areas) identifying 1 to 5 gangs. The estimated number of gang members per community ranged from 4 to 750 , with 32 percent of respondents stating there were 25 or fewer gang members in their community.

To illustrate gang activity among Indian communities of different sizes, the following analyses compared communities with a population of 2,000 or more (referred to as "larger communities") and communities with a population of fewer than 2,000 ("smaller communities"). ${ }^{6}$ Seventeen percent of the smaller communities responding to the survey reported experiencing a gang problem, compared with 69 percent of larger communities. Figures 5 and 6 (pages 6 and 7) show the reported

\footnotetext{
5 "Jurisdiction" is defined as the service area of the responding law enforcement agency.
}

6 The mean population of Indian communities for which population data were available was used to determine the population split for larger and smaller communities 


\section{Figure 2: Percentage of Respondents Reporting Youth Gang Activity in 2000, by Sample}

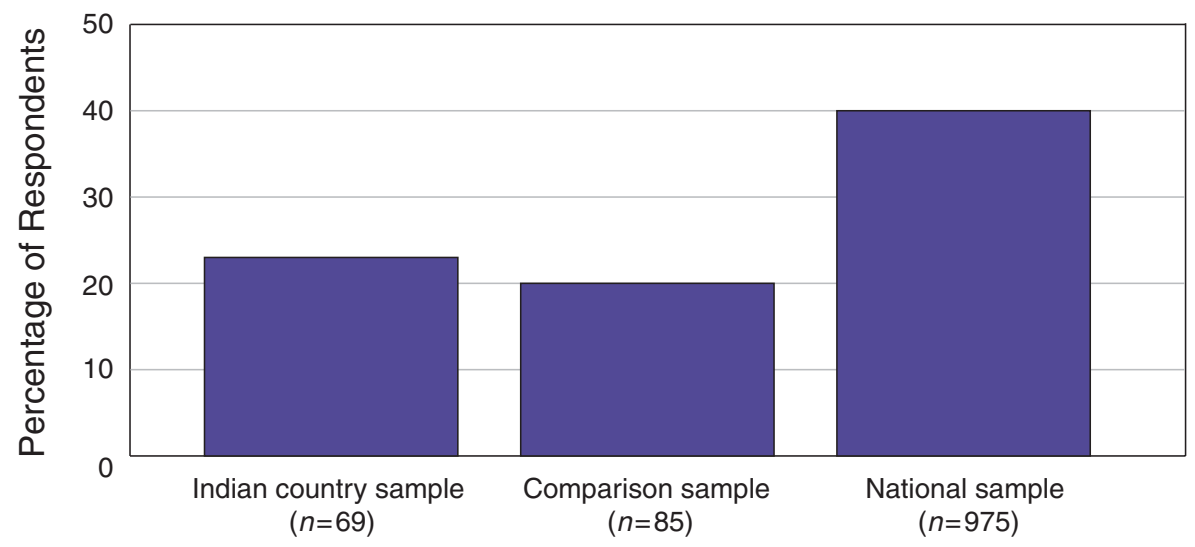

Source: 2000 Survey of Youth Gangs in Indian Country; 2000 National Youth Gang Survey.

\section{Figure 3: Number of Gangs Reported by Indian Country Communities, $2000(n=69)$}

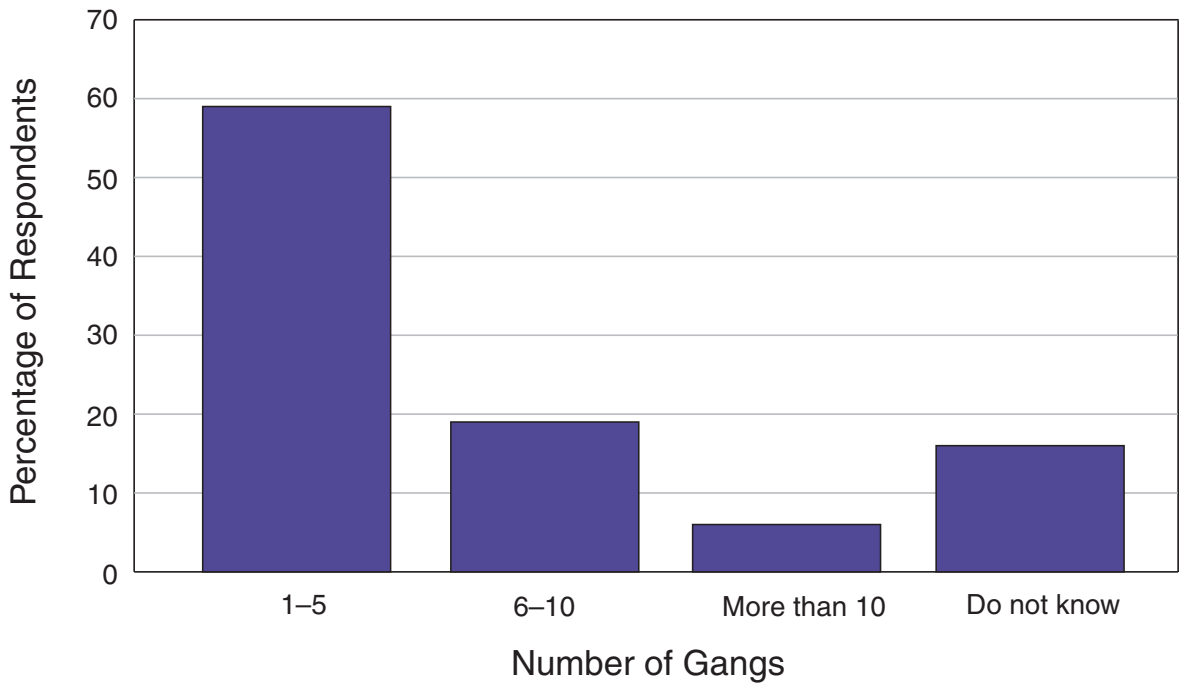

Source: 2000 Survey of Youth Gangs in Indian Country.

number of gangs and gang members, respectively, by community size. Not only did a greater proportion of larger communities report gang activity, these communities were also more likely to report greater numbers of active gangs and gang members per community.

\section{Gang Problem Onset}

Of the Indian country respondents who experienced gang activity in 2000 , half said gang problems began after 1994, suggesting the relatively recent onset of gang activity. Approximately half of respondents from the comparison sample indicated that the problems began after 1994. Figure 7 (page 7) shows the percentage of respondents from each sample who first identified a gang problem in their community during a particular year. The figure suggests that gang activity began later in the Indian country and comparison samples than in the national sample and is not the longstanding problem that is more frequently reported by national survey respondents.

The onset of gang activity is associated with a variety of factors. Findings from a field study on gangs in the Navajo Nation indicate that the importation and spread of youth gangs are facilitated by specific structural factors in the community (Armstrong et al., 2002). These factors include the frequency with which families move off and onto the reservation; poverty, substance abuse, and family dysfunction; the development of cluster housing instead of traditional single-family housing; and a waning connection to Native American culture and traditional kinship ties among cousins. These findings reflect a process of "multiple marginalization," whereby depressed "social and economic conditions result in powerlessness" among community members (Vigil, 2002:7). These changes in structural forces weaken families, schools, and other institutions traditionally associated with social control, thus allowing youth to be socialized on the street by gangs. For example, respondents in the Navajo gang study cited friendship and the sense of belonging to something as significant benefits derived from being in a gang (Armstrong et al., 2002). Related research indicates that gang activity in Indian country communities is a relatively recent phenomenon and is associated with the social and structural conditions of larger communities (Conway, 1998; Hailer, 1998). NYGC survey findings corroborate many of these findings.

\section{Gang Member Demographics}

Communities that reported gang activity in 2000 were asked to estimate demographic characteristics of gang members, including age, gender, and race or ethnicity. ${ }^{7}$ Respondents said that 80 percent of gang members in Indian country were male and 20 percent were female. Not

7 Survey questions regarding demographic data about gang members required respondents to estimate the percentage of gang members who met certain criteria. Ideally, the percentages would be weighted by the total number of gang members reported in a community to reflect differences in membership across the reporting communities. Given the available data, the results in this Bulletin are based on unweighted data because of the significant reduction in eligible cases for weighting procedures. Caution must be exercised when interpreting the results, and any comparisons with studies where results are based on weighted data must be done with these concerns in mind. However, comparing results derived from unweighted data with those derived from weighted data in this survey demonstrates only slight variation, providing confidence in the findings reported here. 


\section{Figure 4: Number of Gang Members Reported by Indian Country}

Communities, $2000(n=69)$

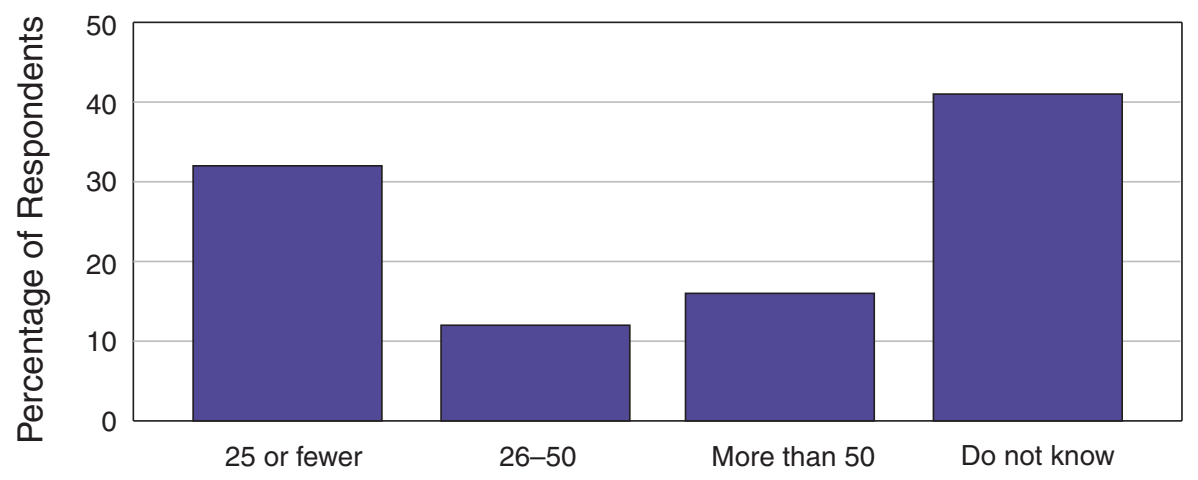

Number of Gang Members

Source: 2000 Survey of Youth Gangs in Indian Country.

Figure 5: Number of Gangs Reported by Indian Country Communities, 2000, by Community Size*

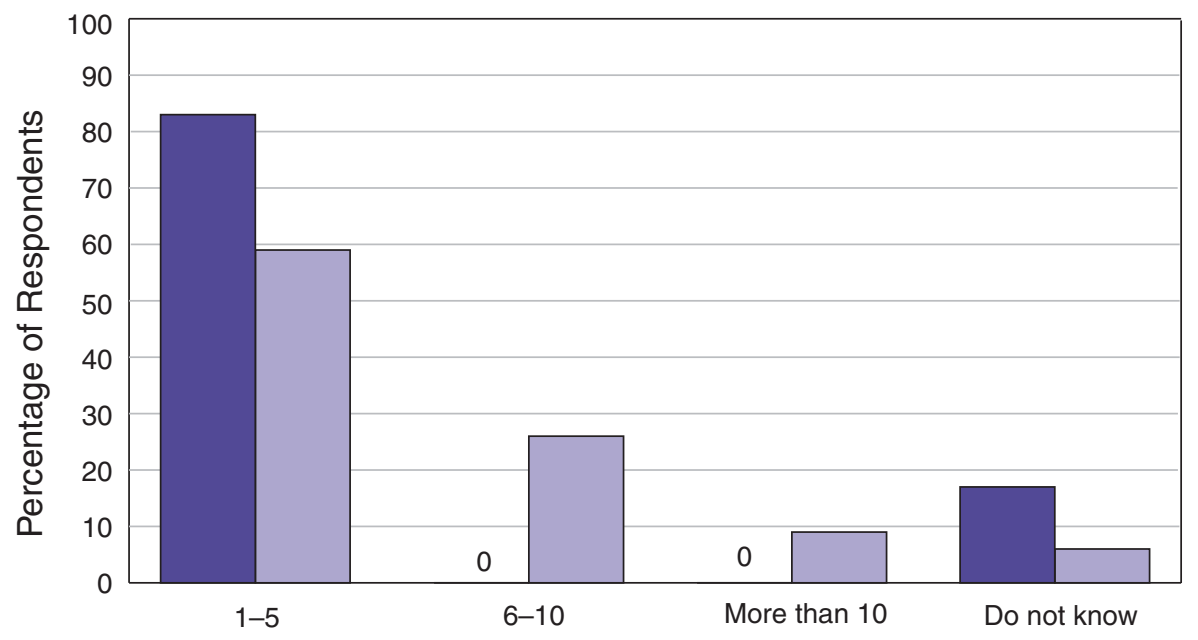

Number of Gangs

Smaller communities $(n=23)$

Larger communities $(n=34)$

*Smaller communities have a population of less than 2000; larger communities 2000 or more. Source: 2000 Survey of Youth Gangs in Indian Country.

surprisingly, survey respondents also believed the majority (78 percent) to be American Indian, Alaska Native, or Aleut. In fact, approximately one-half of responding communities indicated almost all gang members (more than 90 percent) were of this race. Twelve percent of gang members were reported to be Hispanic/Latino, followed by Caucasian/white (7 percent),
African American/black (2 percent), and Asian (2 percent). Respondents indicated that approximately one-quarter of gang members in their community were younger than 15 years old and that almost half were between 15 and 17 years old, suggesting that nearly 75 percent of all reported gang members in Indian country were juveniles (younger than 18 years old).
As seen in figures 8 and 9 (page 8), the findings related to gender and age makeup for the Indian country sample are consistent with those for the comparison sample. ${ }^{8}$ Twenty percent of the gang members in the comparison sample were female, compared with 6 percent in the national sample (Egley, 2002). Respondents for the comparison sample reported a greater percentage of juvenile gang members (70 percent), compared with 37 percent reported nationally in 2000 (Egley, 2002).

These data suggest that youth gangs in Indian country and the comparison sample are similar in age and gender composition. Additionally, these findings are consistent with previous research that has found that areas experiencing a recent onset of gang activity frequently have larger proportions of juvenile and female gang members than areas with longstanding gang problems (Howell, Egley, and Gleason, 2002). Respondents also estimated that 82 percent of the identified gangs in Indian country included both male and female members, 10 percent were female dominated (more than 50 percent of the gang's members were female), and 35 percent were racially or ethnically mixed. Gangs with such a demographic mixture are sometimes referred to as "hybrid" gangs and are increasingly visible across the country (Starbuck, Howell, and Lindquist, 2001).

\section{Gangs in Schools}

The survey asked respondents about gang activity in community schools. Eighty-six percent of the Indian country communities with gang problems indicated gang activity in one or more community high schools. Additionally, 74 percent said gangs were active in one or more community middle schools, and 42 percent indicated youth gang activity in one or more community elementary schools. Howell and Lynch (2000) report that youth gangs are linked with serious crime problems in schools across the country. Those schools in which gang activity was reported were also more likely to have higher levels of violent victimization, availability of drugs, and students who carry guns than schools reported not to have gang activity. Gang member interviews from the study of gangs in the Navajo Nation indicated that half of gang members were currently

8 To reflect differences in membership across the reporting jurisdictions, data from the national and comparison samples are weighted by the total number of gang members reported in a community. 
enrolled in school (Armstrong et al., 2002). Given the risk of criminal activity associated with gangs in schools, these findings highlight the importance of school-based gang prevention and intervention programs.

\section{Gang Migration}

The survey defined "gang migrants" as youth gang members who "already have joined gangs in their former jurisdiction prior to their arrival in a new jurisdiction." Survey respondents were asked to estimate the percentage of gang members who were migrants. Approximately 17 percent of all gang members were identified as such, and the majority of respondents (77 percent) perceived migration to be tied to social circumstances such as gang members moving back into the community with their families. These results are consistent with reports by law enforcement agencies outside of Indian country (Egley, 2000; Maxson, 1998). Comparatively few respondents said gang members migrated to their community for criminally motivated reasons such as establishing drug markets, avoiding law enforcement, or establishing an alliance with Native American gangs.

\section{Criminal Involvement}

Survey respondents provided information about where Indian country gang members committed their crimes. The majority of respondents (56 percent) reported that youth gangs committed their crimes both within and outside the community, whereas 36 percent reported that crimes were committed only inside Indian country.

The survey asked respondents about the proportion of gang members involved in a variety of criminal offenses. According to respondents, gang members were most frequently involved in graffiti (47 percent of communities with a gang problem reported a high degree of involvement in this offense), vandalism (40 percent), drug sales (22 percent), and aggravated assault (15 percent) (figure 10). These findings support earlier research that suggests that gang involvement in criminal activity in Indian country consists mainly of property crime (Armstrong et al., 2002).

Indian country gang members who commit assaults tend not to use firearms in these crimes. Twice as many communities reported that gang members use weapons other than firearms in conjunction with assault crimes.

\section{Figure 6: Number of Gang Members Reported by Indian Country Communities, 2000, by Community Size*}

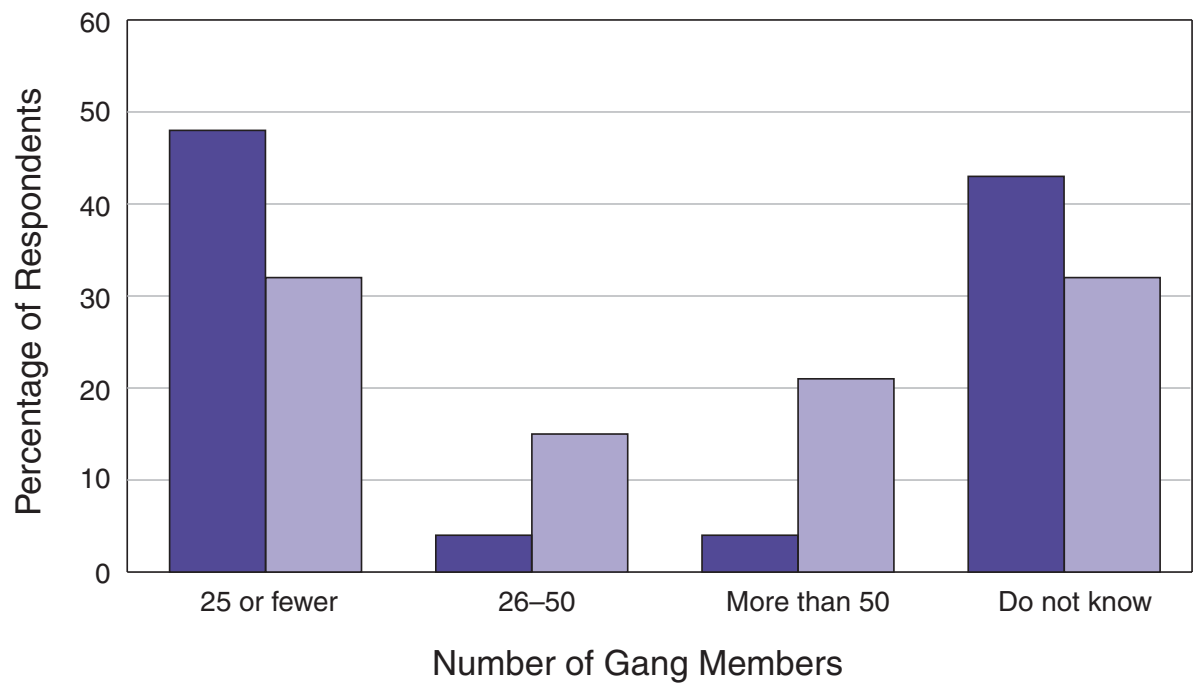

Smaller communities $(n=23)$

Larger communities $(n=34)$

*Smaller communities have a population of less than 2000; larger communities 2000 or more. Source: 2000 Survey of Youth Gangs in Indian Country.

Figure 7: Year of Onset of Gang Problems, by Survey Sample

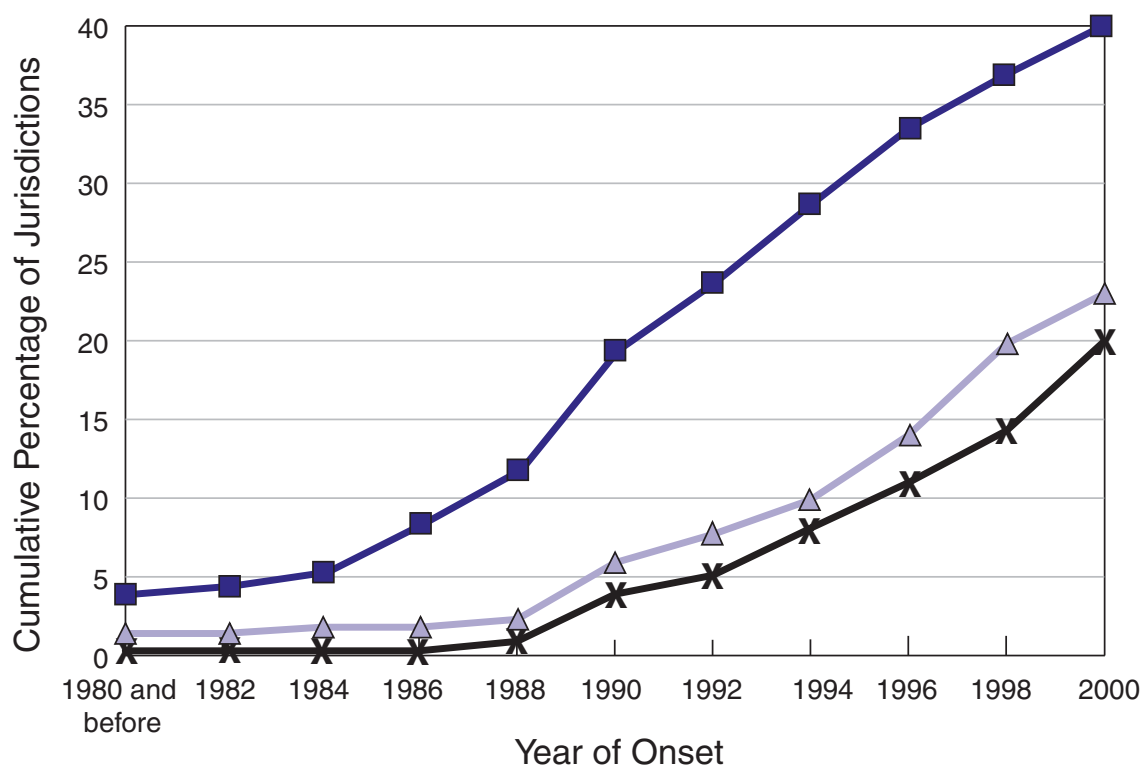

* Comparison sample $\Delta$ Indian country sample $\quad \rightarrow$ National sample Source: 2000 Survey of Youth Gangs in Indian Country; 2000 National Survey of Youth Gangs. 


\section{Figure 8: Gender of Gang Members, 2000, by Sample}

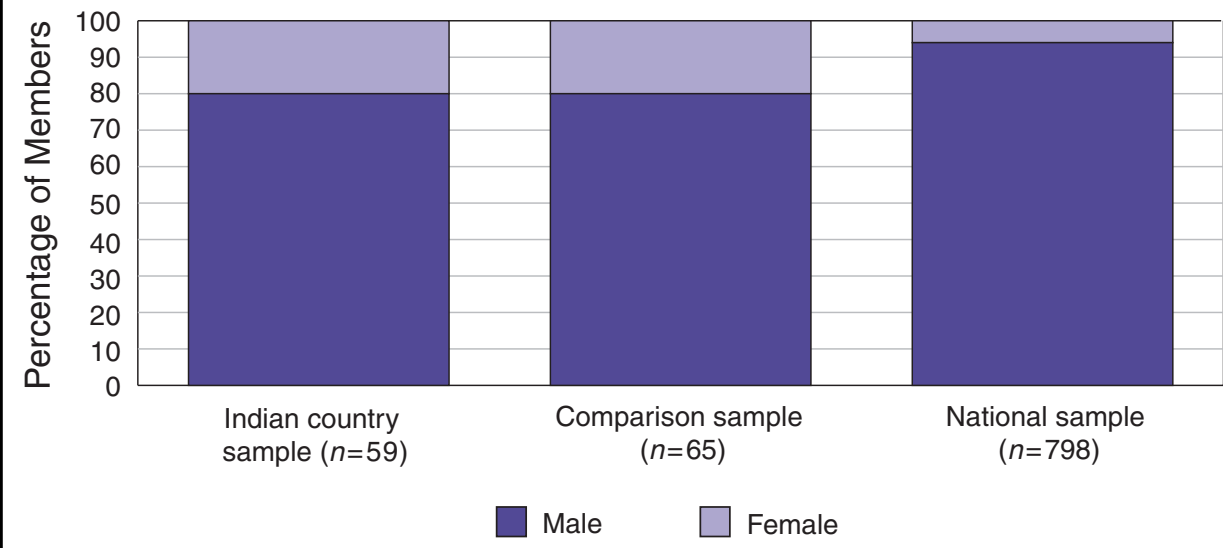

Source: 2000 Survey of Youth Gangs in Indian Country; 2000 National Youth Gang Survey.

\section{Figure 9: Age of Gang Members, 2000, by Sample}

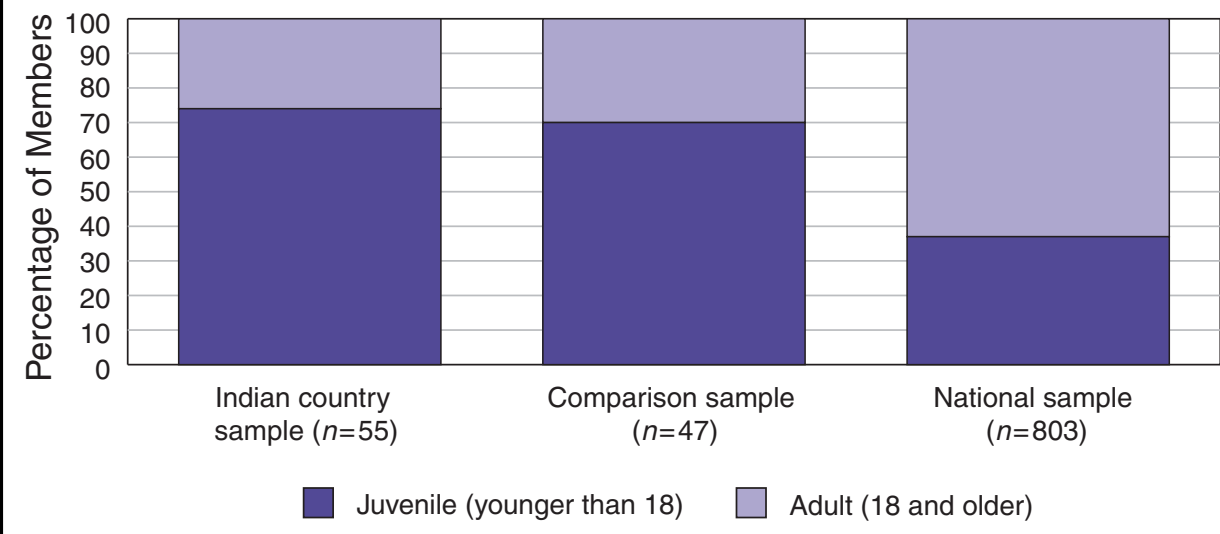

Source: 2000 Survey of Youth Gangs in Indian Country; 2000 National Youth Gang Survey.

The majority of respondents from communities in all samples reported no gangrelated homicides during 2000 , and few Indian country and comparison sample respondents indicated more than one gang-related homicide (figure 11). By contrast, nearly one-quarter of respondents from the national sample reported more than one gang-related homicide.

It is important to note that although the reported level of violent criminal behavior by gang members in Indian country is relatively low, the level of criminal activity increases with the size of the community. Figure 12 (page 10) shows that in the larger communities, respondents reported more gang member involvement in both property and violent crimes. Additionally, 26 percent of larger communities reported one or more gang-related homicides in 2000 , compared with only 6 percent of smaller communities.

Interviews with youth in the Navajo study showed that most gang crime incidents in Indian country are nonviolent (Armstrong et al., 2002). Navajo youth who identified with gang culture focused primarily on values of antioppression, cohesion within the gang family, and participation in leisure activities-not criminal enterprises. Members of Navajo reservation gangs indicated that most criminal activity, whether drug sales or violence, was individually motivated rather than gang motivated (Armstrong et al., 2002). Alcohol use, graffiti, and vandalism were the primary crimes Navajo gang members engaged in as a gang, which is consistent with the current survey findings. In fact, 83 percent of respondents in the Indian country survey said that only very little or some of the youth crime in their communities involves gang members.

\section{Influences on Community Gang Activity}

Fifty-one percent of Indian country respondents reported that gang members returning to the community from prison in 2000 had a negative impact on local youth gang problems. Thirty-one percent reported very little impact, and 18 percent reported no impact. These findings are comparable to those outside Indian country, suggesting that a majority of communities, regardless of size or location, are negatively affected by gang members returning from prison (Egley and Arjunan, 2002).

To explore other possible sources of gang influence, the survey asked respondents how much their community's gang problem was affected by gang activity in outside areas. Fifty-three percent of responding communities said gang activity in large cities influenced the nature of gang activity in their community. Other sources of influence included border towns (24 percent), outside schools (22 percent), and prisons and jails (15 percent).

NYGC further explored the association between gang activity in Indian country communities and the proximity of the communities to large cities. ${ }^{9}$ Of respondents reporting an urban influence, 70 percent were located within 120 miles of a large city with gang activity, suggesting that such Indian country communities are more susceptible to the effects of largecity gang activity. However, as with earlier research (Hailer, 1998), these data also indicate that distance and isolation from

\footnotetext{
9 The survey did not specify the influence of a large nearby city. Therefore, respondents might have interpreted the question as general influence of large urban areas, not specifically those located near their community. For example, one respondent from a community located almost 400 miles from the nearest city reported the community's gang problem was heavily influenced by gang activity in large cities. A closer look at Indian country communities that reported little or no influence from city gang activity, despite close proximity to cities, might provide useful information about the factors that enable those communities to prevent gang activity from influencing local youth and the community.
} 


\section{Figure 10: Criminal Activities of Gang Members in Indian Country, $2000(n>65)$}

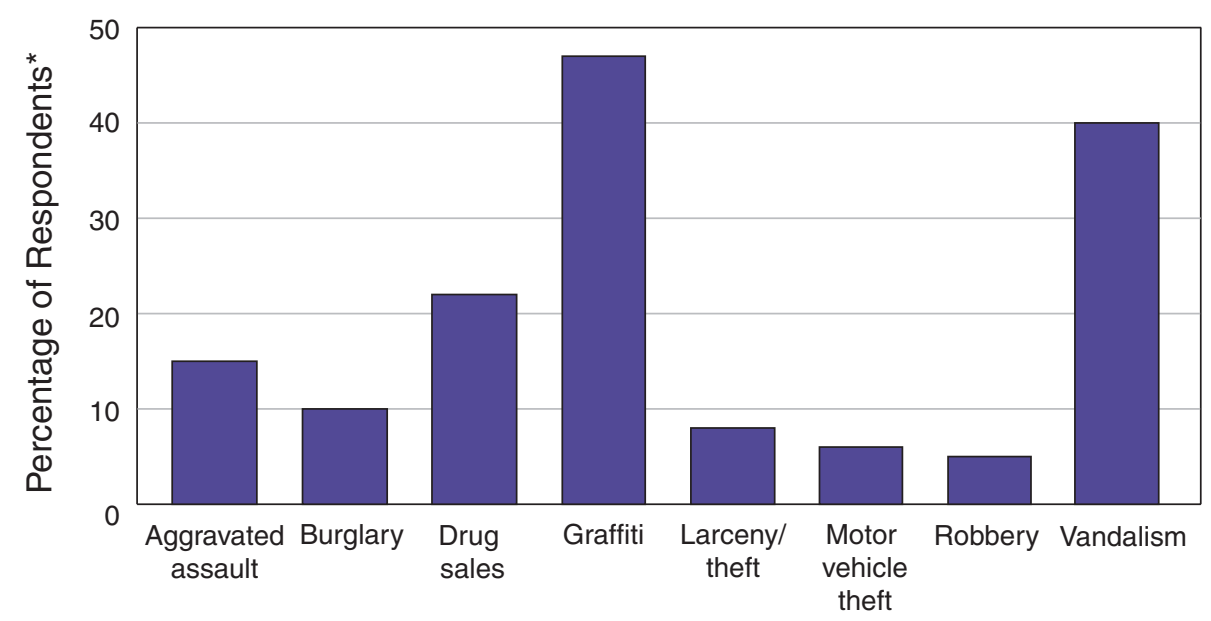

"Data reflect crimes in which respondents said "most/all" gang members were involved. Source: 2000 Survey of Youth Gangs in Indian Country.

\section{Figure 11: Number of Gang-Related Homicides in 2000, by Sample}

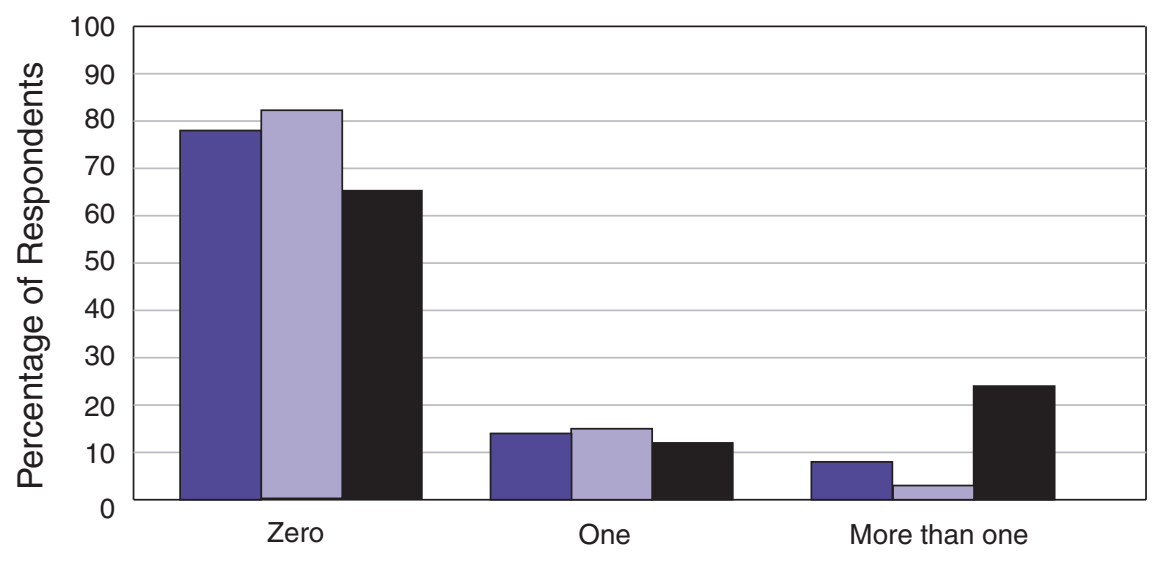

Number of Homicides

Indian country sample $(n=59)$
Comparison sample $(n=65)$
National sample $(n=646)$

Source: 2000 Survey of Youth Gangs in Indian Country; 2000 National Youth Gang Survey.

large cities do not insulate Indian country communities from the influence of large cities' gang activity.

Factors contributing to the persistence of gang activity in Indian country communities most often included the spread of the gang culture from nearby cities and towns (37 percent of respondents). Other contributing factors reported by respondents include parental apathy, erosion of the family structure, lack of values and low self-esteem among youth, social problems other than poverty (mainly drug and alcohol abuse but also unemployment, child abuse, and domestic violence), and a lack of positive activities for youth.
Survey respondents also identified factors that prevent youth in their community from joining gangs. Respondents cited positive activities for youth, community and school programs that address violence and gang activity, and traditional Indian culture and beliefs. Youth gang activity in the Navajo Nation was found to be influenced by similar factors. Researchers found that some gang-involved Navajo youth returned from urban settings and influenced peers in the community. Often these youth resided in subsidized public housing communities where numerous other youth and their families shared the same family and community factors of multiple marginality (see discussion of these factors on page 5). In this way, some youth who have never lived off the reservation in communities with gangs are exposed indirectly to the gang culture. This pattern of youth becoming involved in gangs is consistent with research that suggests that the diffusion of popular media and culture contributes to the proliferation of gang activity (Klein, 1995). The relocation of gang members as they moved with their families out of the cities (Maxson, 1998), movies glorifying youth gangs (such as Colors), and the popularity of "gangsta" rap music appear to have worked together to introduce large-city gang culture to youth in the suburbs and areas far away from central cities.

\section{Defining Youth Gangs}

The characteristics that guide local definitions of "youth gang" often vary among law enforcement agencies (NYGC, 2000). To examine this issue in Indian country, respondents were asked to rank six characteristics according to their importance in defining a youth gang in their community. As shown in the table (page 10), the average rank for each characteristic is approximately 3 to 4 , whereas a ranking of 1 or 2 would indicate greater importance.

No one characteristic emerges as dominant over the others-considerable variation exists among communities as to the most important criteria for defining a youth gang. However, the average rank of "commits crime together" is significantly lower among Indian country respondents than among comparison sample respondents. This suggests that group criminal activity is a less defining feature of youth gangs in Indian country. This result may be related to the developing nature of youth gangs and youthful experimentation with gang identity in Indian country. 


\section{Figure 12: Criminal Activities of Gang Members in Indian Country, 2000, by Community Size*}

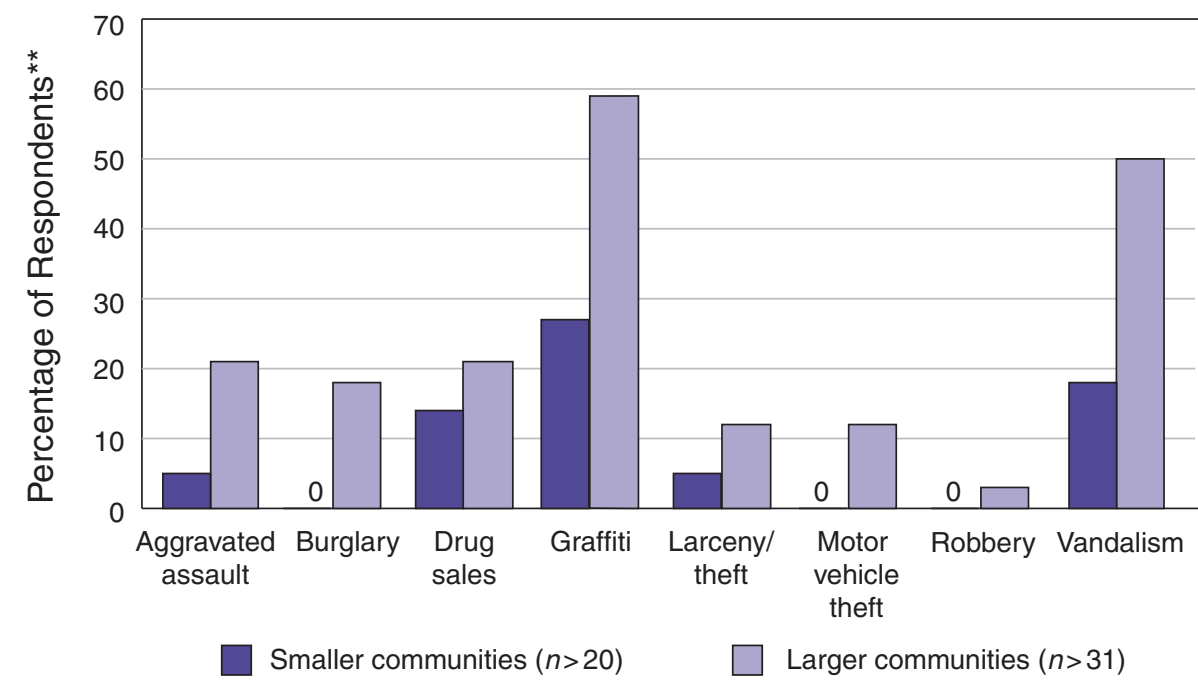

*Smaller communities have a population of less than 2000; larger communities 2000 or more.

**Data reflect crimes in which respondents said "most/all" gang members were involved.

Source: 2000 Survey of Youth Gangs in Indian Country.

\section{Characteristics Used in Defining a Youth Gang}

\begin{tabular}{lcc} 
& \multicolumn{2}{c}{ Average Rank (1=Highest, 6=Lowest) } \\
\cline { 2 - 3 } Gang Characteristic & $\begin{array}{c}\text { Indian Country Sample } \\
(\mathbf{n}=\mathbf{5 6})\end{array}$ & $\begin{array}{c}\text { Comparison Sample } \\
(\mathbf{n}=\mathbf{4 5})\end{array}$ \\
\hline Claims a turf or territory & 3.9 & 4.3 \\
Commits crime together & 3.6 & 2.4 \\
Has a leader or several & 3.5 & 3.4 \\
leaders & 3.4 & 3.5 \\
Has a name & & \\
Displays or wears common & 3.3 & 4.0 \\
colors or other insignia & 3.2 & 3.4 \\
Hangs out together & &
\end{tabular}

Source: 2000 Survey of Youth Gangs in Indian Country; 2000 National Youth Gang Survey.

\section{Social Problems in the Community}

Much of the literature about Indian country communities, along with input from advisory group members and practitioners in the field, suggests that social conditions in these areas are often associated with violence and victimization (Armstrong et al., 2002; Conway, 1998; Hailer, 1998). Thus, survey respondents were asked to rate the seriousness of various social problems in the community. Figure
13 reveals that 96 percent of respondents reported alcohol abuse as a significant problem, followed by drug abuse (88 percent) and domestic violence (80 percent). Of the eight social problems respondents were asked to rate, youth gangs ranked second to last as a serious problem (by 52 percent of communities) and violent juvenile crime ranked last (42 percent).

Although gang activity does not generally appear to be a serious problem relative to other social conditions in Indian country communities, 65 percent of larger communities said the gang problem was serious or very serious, compared with 35 percent of smaller communities. Other problems, including substance abuse and domestic violence, were recognized as significant problems across communities, regardless of size.

\section{Perceptions of the Youth Gang Problem}

Forty-nine percent of responding communities said that the magnitude of their youth gang problem was about the same in 2000 as it was in 1999. Thirty-four percent said it had worsened and 17 percent said it had improved.

\section{Implications for Program and Policy Responses}

Findings from NYGC's Survey of Youth Gangs in Indian Country add to the current understanding of gang activity in these areas and have important implications for policy and practice regarding tribal youth. In general, the intensity of the gang problem and the severity of gang members' criminal involvement are relatively low. The majority of the survey respondents appear to experience gang problems similar to those in less populated communities throughout the nation. Based on this finding, it is possible to recommend prevention, intervention, and suppression programs for Indian communities by considering programs that have successfully targeted delinquent activity and gang involvement in the general population.

For example, because the majority of Indian country communities say their gangs are in the early stages of developmentand because delinquent behavior is a strong predictor of gang membershipprograms that prevent delinquency are likely to reduce gang involvement (Howell, Egley, and Gleason, 2002). Delinquency prevention programs that help youth develop social skills, provide opportunities to use them, and recognize youth for successfully implementing them may help prevent delinquency involvement (Catalano and Hawkins, 1996). However, it is important to remember that although these programs have shown promise, most have not been tested with an Indian population. Therefore, these programs may need to be adapted to better address 


\section{Figure 13: Perceived Seriousness of Social Problems in Indian Country Communities in $2000(n=69)$}

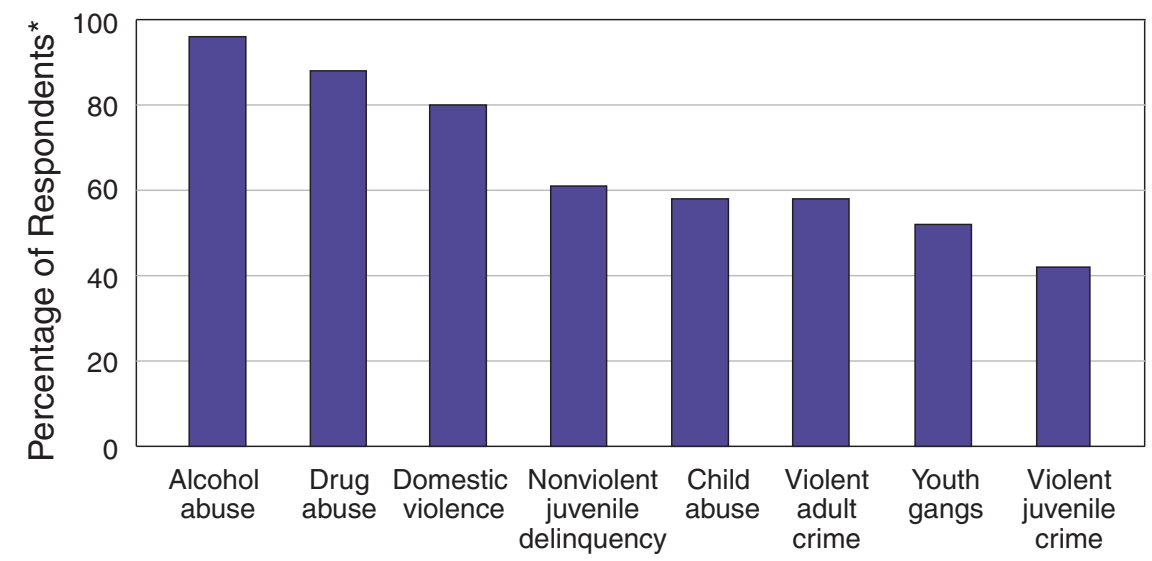

*Data reflect percentage of respondents who rated a social problem "serious" or "very serious." Source: 2000 Survey of Youth Gangs in Indian Country.

issues faced by Indian populations and to evaluate their effectiveness in this setting.

\section{A Comprehensive Approach}

Survey findings suggest that the most critical concerns in Indian country communities are the social problems that contribute to youth gang involvement, not gangs themselves. Respondents identified a variety of factors that promote delinquent behavior and gang activity, including parental apathy, erosion of family structure, low self-esteem, social problems in the community, and lack of positive activities for youth. Therefore, programs incorporating a range of strategies to prevent, control, and reduce youth crime in Indian country could effectively combat gangs. Although the likely focus of most Indian country communities will be prevention programs, community members should consider all three levels (i.e., prevention, intervention, and suppression), especially in larger communities where gang problems were reported to be more serious.

Further, community-specific strategies for combating youth gangs are most beneficial when based on a detailed assessment of the local gang problem. NYGC has developed both an assessment protocol and a comprehensive model for preventing and combating gang membership and activity that consists of a continuum of prevention, intervention, and suppression strategies (NYGC, 2002a, 2002b). It is particularly important that all community agencies collaborate in combining resources to develop the most comprehensive and effective approach to combating local gang problems (Howell, Egley, and Gleason, 2002; Starbuck, Howell, and Lindquist, 2001).

\section{Prevention}

Described below are prevention programs that target the general population and seek to prevent delinquency and violence, which can be stepping stones to gang membership. Most of these school-based programs include a parental training and involvement component and focus on preventing general violence and building prosocial skills. It is important to note that these programs have not been evaluated specifically for their effects on potential gang involvement (Catalano et al., 1998) and, with the exception of two substance abuse programs, none of these programs has been evaluated specifically for effectiveness with Indian country youth.

General delinquency. A wide variety of classroom violence prevention curriculums are being implemented in schools across the country, and many of these have proven effective (Gottfredson, 2001). Selected programs are briefly described here (many others are reviewed in Howell, 2003). Programs selected for inclusion here have reasonable implementation potential in Indian country, particularly in the more populated areas.
Responding in Peaceful and Positive Ways (RIPPW) is an effective violence prevention curriculum for middle school students (Farrell and Meyer, 1997, 1998). The program builds knowledge, changes attitudes, and enhances youth skills for acting against violence. It also teaches children about the nature of violence and its consequences. The curriculum, which consists of 18 sessions over the course of 1 semester, teaches sixth grade students strategies for negotiating interpersonal conflicts nonviolently. Adult role models trained in the curriculum administer the weekly sessions. Peer mediation, teambuilding activities, small group work, and role-playing activities are used regularly. RIPPW appears to affect males and females differently, with boys-but not girls-exhibiting lower levels of violent behavior (e.g., fighting, threatening to hurt someone, or carrying weapons), suppressed anger, assault against teachers, and school suspensions. Girls showed improvements in problem solving.

Law-Related Education (LRE) (www. streetlaw.org) consists of $\mathrm{K}-12$ classroom instruction designed to educate youth about the origin and role of law in key social systems, such as the family, community, school, and juvenile and criminal justice systems. LRE programs draw practical connections among the everyday lives of young people and the law, human rights, and democratic values. LRE programs have been effective in improving academic performance and preventing general delinquency (Maguin and Loeber, 1996). In addition, some evidence shows that LRE prevents aggressive behavior (Gottfredson, 1990; Johnson and Hunter, 1985).

Promoting a safe school environment and making all students feel safe may reduce the risk of gang involvement, but traditional school security measures such as security guards, metal detectors, and locker checks do not appear to be a solution, in and of themselves, to gang problems (Gottfredson and Gottfredson, 2001; Howell and Lynch, 2000). Additional interventions are needed. The Safe Schools Unit of the San Diego County (CA) Office of Education has developed a promising practical approach for increasing school safety and intervening in student conflicts, particularly gang-related situations (Sakamoto, 1996). The Safe Schools Unit has a Violence Prevention/Intervention (VPI) team that helps schools develop comprehensive safety plans. In addition 
to outlining school safety policies, procedures, and crisis response protocols, these plans include training teachers, students, and parents to address gangs and violence. The VPI team also operates a Rapid Response Unit that assists schools during crisis situations. This comprehensive approach, along with other prevention efforts and a history of multiagency partnerships, has improved the safety of San Diego schools.

A national assessment of school-based gang prevention and intervention programs (Gottfredson and Gottfredson, 2001) concluded that many of them address gang involvement but that most of them are not well implemented. Nevertheless, consideration should be given to effective classroom violence prevention curriculums (Gottfredson, 2001) that can easily be added to traditional instruction in schools in Indian country.

Gang involvement. Survey respondents said community and school programs that addressed violence and gang activity were effective ways to prevent community youth from becoming involved in gang activity. As such, the Gang Resistance Education and Training (G.R.E.A.T.) program ${ }^{10}$ may be an appropriate way to effectively reduce gang involvement in Indian country. Uniformed law enforcement officers teach the 13-week course mainly to middle school students (Esbensen and Osgood, 1997; Esbensen et al., 2001). In addition to educating students about the dangers of gang involvement, lessons emphasize cognitivebehavioral training, social skills development, refusal skills training, and conflict resolution. Modified curriculums have been developed for fifth and sixth graders and third and fourth graders. Multisite evaluations of G.R.E.A.T. show the program has small but positive effects on student attitudes and ability to resist peer pressure to join gangs (Palumbo and Ferguson, 1995; Esbensen et al., 2001). For example, students who received G.R.E.A.T. training had less self-reported delinquency, fewer gang affiliations, and greater commitment to school and prosocial peers than students who did not participate in the program (Esbensen et al., 2001). To date, G.R.E.A.T. has been implemented in seven Indian country communities, with the assistance of the National Native American Law Enforcement Association and the Boys \& Girls Clubs of America. Additionally, two

10 For more information about the G.R.E.A.T. program in Indian country, visit www.naclubs.org/main/great.shtml.
G.R.E.A.T. officer training sessions for Bureau of Indian Affairs/Tribal Officers have graduated more than 50 officers, and plans exist for additional sessions in upcoming years.

Substance abuse. Perhaps the most compelling Indian country survey finding was the magnitude of social problems reported, specifically the number of communities citing alcohol abuse and drug abuse as a significant problem (96 percent and 88 percent, respectively). Because of the high incidence of alcohol and drug abuse, this area of prevention is particularly pertinent to the Indian population. The National Institute on Drug Abuse (1997) has identified a number of effective programs for preventing drug use and antisocial behavior among children and adolescents. Two of these programs have been implemented with Indian populations and show good potential for success in those communities.

The Strengthening Families Program is a 7-week curriculum designed to bring parents together with their 10- to 14-year-old children, with the goal of reducing substance abuse and other problem behaviors in youth. The program began as an effort to help substance-abusing parents improve their parenting skills and thus reduce their children's risk factors (Kumpfer and Alvarado, 1998). It contains three elements: a children's skills program, a parent training program, and a family skills training program.

This intervention approach has been evaluated in a variety of settings and with several racial and ethnic groups (Molgaard, Spoth, and Redmond, 2000), including Indian youth and families (Kumpfer, Molgaard, and Spoth, 1996; Molgaard and Spoth, 2001). Youth who completed the program had significantly lower rates of alcohol, tobacco, and marijuana use than youth in the control group. Other positive outcomes included reductions in family conflict, improvement in family communication and organization, and reductions in delinquency. The Iowa Strengthening Families Program, a revision of the initial program model, has been adapted for Indian populations by the Iowa University Extension to Families (www.extension. iastate.edu/sfp).

Preparing for the Drug Free Years (PDFY) is an effective program that decreases problem behaviors among teens by improving parenting practices to reduce risk factors and increase protective factors
(Haggerty et al., 1999). The program's goal is to empower parents of children ages 8 to 14 to reduce the likelihood that their children will abuse drugs and alcohol or develop other common adolescent problems. The flexible PDFY curriculum has been used with a broad range of families of various socioeconomic and cultural backgrounds and is designed to reach adult learners regardless of learning style or level of education. To date, it has been implemented in conjunction with the Iowa Strengthening Families Program and used successfully with American Indian families (Harachi, Catalano, and Hawkins, 1997).

The Midwestern Prevention Project is another successful program for preventing the use of gateway substances (alcohol, cigarettes, and marijuana) among lowand high-risk seventh and eighth graders (Johnson et al., 1990). The program is unique because it addresses all five of the risk factor domains:

- All students are offered individual skills training.

- Parents are provided training and opportunities for direct involvement with their children and their children's schools.

- Peers are involved in positive modeling.

- The school is the central component for drug prevention programming, which includes a variety of social learning techniques, and policies are modified to discourage drug use.

- Community policies and social norms about drug use are modified and clarified to set and reinforce clear behavioral standards.

\section{Intervention}

Intervention programs focus on youth identified as being at risk of becoming delinquent or involved in a gang. These programs also address general delinquency.

General delinquency. The National Court Appointed Special Advocate Association (CASA) implemented the Tribal Court CASA project in 1994 to support programs in which volunteers act as advocates for abused or neglected American Indian and Alaska Native children (Frey, 2002). National CASA oversees two grants that assist tribal court programs: the National Grants Program and CASA Program Development for Native American Tribal Courts. The National Grants Program, administered in partnership with the Office 
of Juvenile Justice and Delinquency Prevention, provides funding to help Indian communities develop and operate CASA programs. CASA Program Development for Native American Tribal Courts provides funds specifically to tribal communities that wish to implement a CASA program. Because problems vary from community to community, the Tribal Court CASA project tailors programs to individual communities' needs. To date, no evaluation of program effectiveness has been performed.

The Boys \& Girls Clubs of America (BGCA) has implemented a number of programs that address important youth issues and that have shown particular promise with at-risk populations (www.bgca.org/ programs). The success of its programs has prompted BGCA to open clubs in Indian country communities. Since the first club opened in Pine Ridge, SD, in 1992, the number of Boys \& Girls Clubs in Indian country has expanded to 123 locations in 23 states, and the clubs serve nearly 80,000 American Indian youth. The Indian country Boys \& Girls Clubs feature tailored programs that improve both the outcomes for youth participating in BGCA and the individual Indian community cultures. BGCA programs in Indian country include SMART Moves (Skills Mastery and Resistance Training, including drug and alcohol prevention and sexual abstinence) and Power Hour (afterschool tutoring) (Fogerty, 2002).

Gang involvement. Targeted Outreach, also operated by BGCA in Indian country, is a communitywide gang prevention program that intervenes with youth at risk for gang involvement, those in the "wannabe" stage, and current gang members. Targeted Outreach incorporates four objectives: community mobilization, recruitment, mainstreaming and programming, and case management. Local implementation of this program begins with mobilizing community leaders and club staff, who discuss local gang issues, clarify their roles, and design a strategy for offering youth alternatives to the gang lifestyle. Police departments, schools, social services agencies, and community organizations recruit at-risk youth into club programs in a nonstigmatizing way through direct outreach efforts and a referral network that links local clubs with courts. Once in BGCA, youth participate in programs based on their individual interests and needs.

The Targeted Outreach initiative has two components: Gang Prevention Through
Targeted Outreach (GPTTO) and Gang Intervention Through Targeted Outreach (GITTO). The components are implemented separately, depending on the severity of gang problems near club locations in a particular city. The respective components try either to prevent high-risk youth from joining gangs (GPTTO) or to provide alternatives to the gang lifestyle by mainstreaming youth into club programming (GITTO).

In the prevention model (GPTTO), youth are recruited to participate in all aspects of Boys \& Girls Club programming. The program has produced generally positive outcomes in behavior related to both school and delinquency measures, although the differences between the comparison group and those participating in the program were stronger for schoolrelated behaviors than for delinquency and gang-related behaviors. Evaluations of youth behavior after participating in GPTTO for 1 year suggested that more frequent attendance was associated with a reduced likelihood of youth wearing gang colors, having contact with the juvenile justice system, and exhibiting delinquent behaviors. Frequent attendance was also associated with improved school outcomes and higher levels of positive peer and family relationships (Arbreton and McClanahan, 2002).

In the intervention model (GITTO), youth are recruited to participate in a project staffed by the Boys \& Girls Club but run separately from daily club activities (either after typical club hours or on a one-on-one basis). Programs are offered in five core areas: character and leadership development, education and career development, health and life skills, the arts, and sports, fitness, and recreation. Like GPTTO, GITTO has produced modest positive outcomes for youth participating in the program. More frequent attendance at GITTO was associated with less involvement in gang-associated behaviors, less contact with the juvenile justice system, and more positive school engagement (Arbreton and McClanahan, 2002).

\section{Suppression}

Suppression techniques are aimed at individuals who are already gang members or participating in criminal activity (Howell, 2000) and involve the police, courts, and corrections. Law enforcement officers have combatted gangs with specialized gang units, prosecution, specialized probation programs, and ordinances such as curfew laws, antiloitering laws, and civil injunctions (Curry and Decker, 2003; Esbensen, 2000; Howell, 2000).

Juvenile courts can make a significant contribution to reducing gang involvement. An effective juvenile probation program in Peoria County, IL, targets juvenile offenders who have been placed on probation for gang-related behavior or substance abuse (Adams, 2002). The program consists of several elements essential to intensive supervision probation, including small caseloads, frequent contacts with probationers, distinct and graduated phases to structure movement through the program, substance abuse assessments, rehabilitation programs, and behavioral controls. Evaluation of the program has demonstrated positive effects; nearly 60 percent of program participants were not charged with a new criminal offense, and approximately 65 percent did not receive any technical violations while in the program.

\section{Implementing a Continuum of Programs}

A number of grant programs have been implemented to help Indian country communities develop prevention, intervention, and suppression programs that address juvenile delinquency, violence, and victimization. OJJDP's Tribal Youth Program (TYP), dedicated to preventing and controlling delinquency and improving the juvenile justice system in American Indian communities (Andrews, 1999), is one such program. Through grant funds, training, and technical assistance, TYP works to meet the unique needs of individual communities by-

- Reducing, controlling, and preventing crime by and against tribal youth.

- Providing interventions for courtinvolved youth.

- Improving tribal juvenile justice systems.

- Providing alcohol and drug-use prevention programs.

To date, 161 tribal communities have received TYP funding. The Michigan Public Health Institute, in partnership with the Native American Institute at Michigan State University, is currently helping five tribes evaluate programs they developed with TYP funds (Fung and Wyrick, 2001). Because communities have used these resources in varying ways, not all programs have been evaluated. 
The Native American Alliance Foundation (NAAF) was awarded a cooperative agreement to provide American Indian and Alaska Native tribes with training and technical assistance to develop or enhance their juvenile justice systems. A primary responsibility of this program is to offer effective, culturally appropriate training and technical assistance that addresses the problems faced by Indian youth and their families. Through such training, NAAF helps communities in Indian country develop a more comprehensive approach to addressing juvenile delinquency, violence, and victimization.

\section{Summary}

In the past few years, a growing concern about crime, delinquency, and gang activity in Indian country has emerged. Previous research shows that much of the gang activity seems to be an expression of youthful experimentation with gang identity and that a strained social environment, the appeal of popular culture surrounding gang activity, and a lack of positive activities for youth contribute to the American Indian youth gang phenomenon (Armstrong et al., 2002).

Few research studies have focused specifically on the level of youth gang activity in these communities. This study has provided a detailed national assessment of gang activity in Indian country communities that can guide effective response to the problem. Findings in this Bulletin reveal that 23 percent of responding Indian country communities experienced a youth gang problem in 2000. The size of the youth gang problem varied considerably, with many communities reporting comparatively few youth gangs and gang members. In general, gang members most often were said to be juvenile, male, and involved in property crimes such as vandalism and graffiti. Survey findings indicate that larger communities have a greater number of gangs and gang members, experience more violent crime by gang members (including homicides), and report gang activity as a more serious social problem.

The data presented here help clarify whether, and in what ways, gangs in Indian country are similar or different from other youth gangs. Although the findings for Indian country communities and national sample respondents differed, it is possible to compare Indian country data with data from the comparison sample, whose respondents more closely resemble Indian country communities in size and geographic location. These comparisons suggest similar levels of gang activity and similar gender and age composition of gang members. Additionally, findings from a field study of youth gangs in the Navajo Nation substantiate many of the survey results presented.

This preliminary assessment of the gang problem in Indian country can be used to guide systematic response to gang activity in these communities. However, community-specific strategies should be based on detailed assessments of local gang problems and involve community agencies in a continuum of programs and strategies that focuses on prevention, intervention, and suppression.

A number of programs have effectively reduced delinquency, and some look promising for reducing gang involvement in the general population. Many of these programs could be culturally tailored for an Indian country population and possibly prove equally effective for its youth. School- and community-based programs to prevent, control, and reduce youth crime and violence in general, such as BGCA and G.R.E.A.T., appear promising, as do programs that address substance abuse. Intervention programs, such as the BGCA Targeted Outreach program, may effectively reduce gang involvement in these areas. For communities experiencing a more severe gang problem, suppression tactics that reduce gang-related criminal activity might be necessary. Additionally, as the gang problem in Indian country appears to be an extension of more serious problems, including poverty, substance abuse, and unemployment, policies aimed at improving overall conditions in a community will most likely have a concurrent and positive impact on the community's gang problem.

\section{References}

Adams, S. 2002. The Impact of Intensive Juvenile Probation Programs. Chicago, IL: Illinois Criminal Justice Information Authority.

Andrews, C. 1999. Tribal Youth Program. Fact Sheet. Washington, DC: U.S. Department of Justice, Office of Justice Programs, Office of Juvenile Justice and Delinquency Prevention.

Arbreton, A.J.A., and McClanahan, W.S. 2002. Targeted Outreach: Boys \& Girls Clubs of America's Approach to Gang Prevention and Intervention. Philadelphia, PA: Public/Private Ventures.
Armstrong, T.L., Bluehouse, P., Dennison, A., Mason, H., Mendenhall, B., Wall, D., and Zion, J. 2002. Finding and knowing the gang nayeeField initiated gang research project: The judicial branch of the Navajo Nation. Unpublished final report. Washington, DC: U.S. Department of Justice, Office of Justice Programs, Office of Juvenile Justice and Delinquency Prevention.

Catalano, R.F., Arthur, M.W., Hawkins, J.D., Berglund, L., and Olson, J.J. 1998. Comprehensive community- and school-based interventions to prevent antisocial behavior. In Serious and Violent Juvenile Offenders: Risk Factors and Successful Interventions, edited by R. Loeber and D.P. Farrington. Thousand Oaks, CA: Sage Publications, pp. 248-283.

Catalano, R.F., and Hawkins, J.D. 1996. The social development model: A theory of antisocial behavior. In Delinquency and Crime: Current Theories, edited by J. David Hawkins. Cambridge, England: Cambridge University Press.

Coalition for Juvenile Justice. 2000. Enlarging the Healing Circle: Ensuring Justice for American Indian Children. Report on the 5th Annual Ethnic and Cultural Diversity Training Conference. Washington, DC: Coalition for Juvenile Justice.

Conway, M.K. 1998. Gangs on Indian Reservations. Washington, DC: U.S. Department of Justice, Federal Bureau of Investigation.

Curry, G.D., and Decker, S.H. 2003. Confronting Gangs: Crime and Community, 2d ed. Los Angeles, CA: Roxbury Publishing.

Egley, A., Jr. 2000. Highlights of the 1999 National Youth Gang Survey. Fact Sheet. Washington, DC: U.S. Department of Justice, Office of Justice Programs, Office of Juvenile Justice and Delinquency Prevention.

Egley, A., Jr. 2002. National Youth Gang Survey Trends From 1996 to 2000. Fact Sheet. Washington, DC: U.S. Department of Justice, Office of Justice Programs, Office of Juvenile Justice and Delinquency Prevention.

Egley, A., Jr., and Arjunan, M. 2002. Highlights of the 2000 National Youth Gang Survey. Fact Sheet. Washington, DC: U.S. Department of Justice, Office of Justice Programs, Office of Juvenile Justice and Delinquency Prevention.

Esbensen, F.A. 2000. Preventing Adolescent Gang Involvement. Bulletin. Washington, DC: U.S. Department of Justice, Office of Justice Programs, Office of Juvenile Justice and Delinquency Prevention.

Esbensen, F.A., and Osgood, D.W. 1997. National Evaluation of G.R.E.A.T. Research in Brief. Washington, DC: U.S. Department of Justice, Office of Justice Programs, National Institute of Justice.

Esbensen, F.A., Osgood, D.W., Taylor, T.J., Peterson, D., and Freng, A. 2001. How great is 
G.R.E.A.T.? Results from a longitudinal quasiexperimental design. Criminology and Public Policy 1(1):87-118.

Farrell, A.D., and Meyer, A.L. 1997. The effectiveness of a school-based curriculum for reducing violence among urban sixth grade students. American Journal of Public Health 87:979-984.

Farrell, A.D., and Meyer, A.L. 1998. Social skills training to promote resilience in urban sixth grade students: One product of an action strategy to prevent youth violence in high-risk environments. Unpublished manuscript. Richmond, VA: Virginia Commonwealth University.

Fogerty, M. 2002. Bridging the gap: Boys and Girls Clubs tackle Indian country youth drug problems. American Indian Report, January.

Frey, H.E. 2002. Tribal Court CASA: A Guide to Program Development. Fact Sheet. Washington, DC: U.S. Department of Justice, Office of Justice Programs, Office of Juvenile Justice and Delinquency Prevention.

Fung, C., and Wyrick, P.A. 2001. OJJDP's Program of Research for Tribal Youth. Fact Sheet. Washington, DC: U.S. Department of Justice, Office of Justice Programs, Office of Juvenile Justice and Delinquency Prevention.

Gottfredson, D.C. 1990. Changing school structures to benefit high-risk youths. In Understanding Troubled and Troubling Youth, edited by P.E. Leone. Newbury Park, CA: Sage Publications, pp. 246-271.

Gottfredson, D.C. 2001. Schools and Delinquency. Cambridge, England: Cambridge University Press.

Gottfredson, G.D., and Gottfredson, D.C. 2001. Gang Problems and Gang Programs in a National Sample of Schools. Ellicott City, MD: Gottfredson Associates, Inc.

Greenfeld, L.A., and Smith, S.K. 1999. American Indians and Crime. Report. Washington, DC: U.S Department of Justice, Office of Justice Programs, Bureau of Justice Statistics.

Haggerty, K., Kosterman, R., Catalano, R.F., and Hawkins, J.D. 1999. Preparing for the Drug Free Years. Bulletin. Washington, DC: U.S. Department of Justice, Office of Justice Programs, Office of Juvenile Justice and Delinquency Prevention.

Hailer, J.A. 1998. A loss of traditions: The emergence of American Indian youth gangs. Master's thesis. San Jose, CA: San Jose State University.

Harachi, T.W., Catalano, R.F., and Hawkins, J.D. 1997. Effective recruitment for parenting programs within ethnic minority communities. Child and Adolescent Social Work Journal 14(1):23-39.
Hickman, M. 2003. Tribal Law Enforcement, 2000. Fact Sheet. Washington, DC: U.S. Department of Justice, Office of Justice Programs, Bureau of Justice Statistics.

Howell, J.C. 2000. Youth Gang Programs and Strategies. Summary. Washington, DC: U.S. Department of Justice, Office of Justice Programs, Office of Juvenile Justice and Delinquency Prevention.

Howell, J.C. 2003. Preventing and Reducing Juvenile Delinquency: A Comprehensive Framework. Thousand Oaks, CA: Sage Publications.

Howell, J.C., Egley, A., Jr., and Gleason, D.K. 2002. Modern-Day Youth Gangs. Bulletin. Washington, DC: U.S. Department of Justice, Office of Justice Programs, Office of Juvenile Justice and Delinquency Prevention.

Howell, J.C., and Lynch, J.P. 2000. Youth Gangs in Schools. Bulletin. Washington, DC: U.S. Department of Justice, Office of Justice Programs, Office of Juvenile Justice and Delinquency Prevention.

Johnson, G., and Hunter, R. 1985. Law-Related Education as a Delinquency Prevention Strategy: A Three-Year Evaluation of the Impact of LRE on Students. Boulder, CO: Center for Action Research.

Johnson, C.A., Penz, M.A., Weber, M.D., Dwyer, J.H., Baer, N., MacKinnon, D.P., Hansen, W.B., and Flay, B.R. 1990. Relative effectiveness of comprehensive community programming for drug abuse prevention with high-risk and lowrisk adolescents. Journal of Consulting and Clinical Psychology 58:447-456.

Juneau, S.K. 1997. Indian Country Street Gang Reference Book 1997. Washington, DC: U.S. Department of the Interior, Bureau of Indian Affairs, U.S. Indian Police Academy.

Juneau, S.K. 1998. Gangs in Indian Country. 1998 Annual Report. Washington, DC: U.S. Department of the Interior, Bureau of Indian Affairs, U.S. Indian Police Academy.

Klein, M.W. 1995. The American Street Gang. Oxford, England: Oxford University Press.

Kumpfer, K.L., and Alvarado, R. 1998. Effective Family Strengthening Interventions. Bulletin. Washington, DC: U.S. Department of Justice, Office of Justice Programs, Office of Juvenile Justice and Delinquency Prevention.

Kumpfer, K.L., Molgaard, V.K., and Spoth, R.L. 1996. The "Strengthening Families Program" for the prevention of delinquency and drug use. In Preventing Childhood Disorders, Substance Abuse and Delinquency, edited by R. Peters and R. McMahon. Thousand Oaks, CA: Sage Publications, pp. 241-267.
Maguin, E., and Loeber, R. 1996. Academic performance and delinquency. Crime and Justice 20:145-264.

Maxson, C.L. 1998. Gang Members on the Move. Bulletin. Washington, DC: U.S. Department of Justice, Office of Justice Programs, Office of Juvenile Justice and Delinquency Prevention.

Molgaard, V.K., and Spoth, R.L. 2001. Strengthening Families Program for young adolescents: Overview and outcomes. In Innovative Mental Health Programs for Children, edited by S. Pfeiffer and L. Reddy. Binghamton, NY: Haworth Press, pp. $15-29$

Molgaard, V.K., Spoth, R.L., and Redmond, C. 2000. Competency Training. The Strengthening Families Program: For Parents and Youth 10-14. Bulletin. Washington, DC: U.S. Department of Justice, Office of Justice Programs, Office of Juvenile Justice and Delinquency Prevention.

National Institute on Drug Abuse. 1997. Preventing Drug Use Among Children and AdolescentsA Research-Based Guide. Rockville, MD: National Institutes of Health, National Institute on Drug Abuse.

National Youth Gang Center (NYGC). 2000. 1998 National Youth Gang Survey. Summary. Washington, DC: U.S. Department of Justice, Office of Justice Programs, Office of Juvenile Justice and Delinquency Prevention.

National Youth Gang Center (NYGC). 2002a A guide to assessing your community's youth gang problem. CD-ROM. Tallahassee, FL: National Youth Gang Center. Copies are available from NYGC (www.iir.com/nygc).

National Youth Gang Center (NYGC). 2002b. Planning for implementation. CD-ROM. Tallahassee, FL: National Youth Gang Center. Copies are available from NYGC (www.iir.com/nygc)

Nielson, M.O., Zion, J.W., and Hailer, J.A. 1998. Navajo Nation gang formation and intervention initiatives. In Gangs and Youth Subcultures: International Explorations, edited by K. Hazlehurst and C. Hazlehurst. New Brunswick, NJ: Transaction Publishers.

Palumbo, D.J., and Ferguson, J.L. 1995. Evaluating Gang Resistance Education and Training (G.R.E.A.T.): Is the impact the same as that of Drug Abuse Resistance Education (D.A.R.E.)? Evaluation Review 19(6):591-619.

Sakamoto, W. 1996. Gang and Youth Violence Intervention: Creating a Safe and Secure School Campus. Unpublished manuscript. San Diego, CA: San Diego County Office of Education.

Spergel, I.A., and Bobrowski, L. 1990. Law enforcement definitional conference transcript. Washington, DC: U.S. Department of Justice, Office of Justice Programs, Office of Juvenile Justice and Delinquency Prevention. 
Washington, DC 20531

Official Business

Penalty for Private Use $\$ 300$

Starbuck, D., Howell, J.C., and Lindquist, D.J. 2001. Hybrid and Other Modern Gangs. Bulletin. Washington, DC: U.S. Department of Justice, Office of Justice Programs, Office of Juvenile Justice and Delinquency Prevention.

Vigil, J.D. 2002. A Rainbow of Gangs: Street Cultures in the Mega-City. Austin, TX: University of Texas Press.

Wakeling, S., Jorgensen, M., Michaelson, S., and Begay, M. 2001. Policing on American Indian Reservations. Research Report. Washington, DC: U.S. Department of Justice, Office of Justice Programs, National Institute of Justice.

This Bulletin was prepared under cooperative agreement number 95-JD-MU-K001 from the Office of Juvenile Justice and Delinquency Prevention, U.S. Department of Justice.

Points of view or opinions expressed in this document are those of the author(s) and do not necessarily represent the official position or policies of OJJDP or the U.S. Department of Justice.

The Office of Juvenile Justice and Delinquency Prevention is a component of the Office of Justice Programs, which also includes the Bureau of Justice Assistance, the Bureau of Justice Statistics, the National Institute of Justice, and the Office for Victims of Crime.

\section{Acknowledgments}

Aline K. Major and Arlen Egley, Jr., Ph.D., are Research Associates with the National Youth Gang Center (NYGC), which is operated for the Office of Juvenile Justice and Delinquency Prevention (OJJDP) by the Institute for Intergovernmental Research in Tallahassee, Florida. James C. Howell, Ph.D., is an Adjunct Researcher with NYGC. Barbara Mendenhall is the Assistant Director and Troy Armstrong, Ph.D., is the Director of the Center for Delinquency and Crime Policy Studies at California State University, Sacramento.

The authors would like to thank the members of the Indian Country Survey Advisory Group for their invaluable direction and input, including Chief Allan, Legislative Associate, National Congress of American Indians; Laura Ansera, Tribal Youth Program Manager, OJJDP; Todd Araujo, Deputy Director, Office of Tribal Justice, U.S. Department of Justice; Frank Canizales, Indian Health Service, U.S. Department of Health and Human Services; Roman Duran, First Vice President, National American Indian Court Judges Association; Norena Henry, Director, American Indian and Alaska Native Affairs, U.S. Department of Justice; Velma Mason, Ph.D., Director, Office for Alcohol and Substance Abuse Prevention, Office of the Assistant Secretary for Indian Affairs, Bureau of Indian Affairs, U.S. Department of the Interior; Peter Maybee, Executive Officer, Office of Law Enforcement Services, Bureau of Indian Affairs, U.S. Department of the Interior; Ada Pecos Melton, President, American Indian Development Associates; Dave Nicholas, Office of Law Enforcement Services, Bureau of Indian Affairs, U.S. Department of the Interior; Arlene Wise, Office for Alcohol and Substance Abuse Prevention, Office of the Assistant Secretary for Indian Affairs, Bureau of Indian Affairs, U.S. Department of the Interior; and Emily Wright, Office of Public and Indian Housing, Office of Native American Programs, U.S. Department of Housing and Urban Development.

The authors are grateful to NYGC Director John Moore, other NYGC staff, and Norena Henry for their valuable review of earlier versions of this Bulletin. The authors also would like to thank Phelan Wyrick, Ph.D., Gang Program Coordinator, OJJDP, for making substantive contributions to this publication, and Jonathan Witte of the Juvenile Justice Clearinghouse for his skillful editing of the manuscript. In addition, the authors gratefully acknowledge staff from MGT of America for their assistance in data collection and data entry and Charlene White, Institute for Intergovernmental Research, and Randrick "Kimo" Souza, Mesa Gang Intervention Project (Arizona), for their assistance in contacting survey recipients. Finally, the authors would like to thank the tribal and law enforcement representatives who responded to the survey. 